\title{
Genetic Diversity Analysis among Inbred Lines of Pearl millet [Pennisetum glaucum (L.) R. Br.] Based on Grain Yield and Yield Component Characters
}

\author{
A. Radhika Ramya ${ }^{1}$, M. Lal Ahamed ${ }^{1}$ and Rakesh K. Srivastava ${ }^{2^{*}}$ \\ ${ }^{1}$ Department of Genetics and Plant Breeding, Acharya N G Ranga \\ Agricultural University, Guntur, Andhra Pradesh, India \\ ${ }^{2}$ International Crops Research Institute for the Semi-Arid Crops (ICRISAT), \\ Patancheru, Hyderabad, Telangana, India \\ *Corresponding author
}

\begin{abstract}
A B S T R A C T
Keywords

Genetic divergence,

Pearl millet,

Maintainer (B-)

lines, Restorer (R-)

lines, Principal

component analysis,

Hierarchical cluster analysis.

Article Info

Accepted:

26 May 2017

Available Online:

10 June 2017

An experiment was conducted to assess genetic divergence among 60 inbred lines included 27 maintainer (B-) and 33 restorer (R-) lines of pearl millet based on quantitative data of grain yield and its ten component traits using hierarchical cluster and principal component analysis (PCA). The PCA identified four principal components (PCs) with Eigen value greater than 1.00 and accounted for 70.97 per cent of total variation. Most important traits in PC1 are days to 50 per cent flowering, plant height, ear length, ear diameter, grain yield per plant, fresh stover yield per plant, dry matter yield per plant and grain harvest index and captured 26.85 per cent of total variation. PC2 was represented by ear diameter and dry matter yield per plant and contributed $18.06 \%$ of total variation. Two characters, grain yield per plant and grain harvest index contributed positively on all the first four PCs. Cluster analysis grouped the inbred lines into eight clusters and the characters, plant height, 1000 grain weight, dry matter yield per plant and productive tillers per plant contributed maximum towards genetic divergence. The grouping patterns of parental lines in PCA and cluster analysis were almost in agreement with each other with minor deviations. The study noticed maximum inter cluster distance between lines of cluster I and II with cluster VII, indicating that lines included in these clusters may have high heterotic response and produce better seggregants when used in Pearl millet hybridization programme.
\end{abstract}

\section{Introduction}

Pearl millet [Pennisetum glaucum (L.) R. Br.] Is one most important cultivated cereals in the world, ranking after rice, wheat, maize, barely and sorghum in terms of area planted to these crops (Khairwal et al., 2007). It is grown on about $30 \mathrm{~m}$ ha in more than 30 countries with the majority of this area in Asia (>10 m ha), Africa (about $18 \mathrm{~m} \mathrm{ha}$ ), and Americas ( $>2 \mathrm{~m}$ ha) (Gupta et al., 2015). It exhibits tremendous amount of genetic diversity because its wide distribution across the world, well adoptation under harsh environmental conditions and cross pollinated mechanism with protogynous flowering (Satyavathi et al., 2013 and Singh et al., 2013). Genetic diversity is the basic requirement for any crop improvement programme. Several methods of divergence analysis based on quantitative traits have been proposed to suit various objectives, viz., Mahalanobis $\mathrm{D}^{2}$ analysis, 
Principal component analysis and hierarchical cluster analysis based on Ward's minimum variance method. Evaluation, characterization and classification of genotypes based on estimates of genetic diversity will help to identify diverse parental lines which can be used in hybrid breeding to develop potential hybrids or varieties. Therefore, the present investigation was undertaken to study the nature and magnitude of genetic divergence for grain yield and its component characters among the inbred lines to provide a basis for selection of parents for hybridization in Pearl millet hybridization programme.

\section{Materials and Methods}

\section{Experimental material}

The material used in the experiment comprised of 60 inbred lines selected on the basis of genetic distance obtained from 88 SSR polymorphic markers of 343 inbred lines of Pearl millet. The selected parental lines were procured from Pearl millet Breeding unit, ICRISAT, Patancheru, Telangana, India is given in table 1.

\section{Evaluation of parental lines}

The parental lines were evaluated during rabi, 2015 at Agricultural college farm, Naira, ANGRAU, Andhra Pradesh in a Randomized block design with two replications. The planting was done on ridges which were 45 $\mathrm{cm}$ apart. Each entry was planted in two rows of $2 \mathrm{~m}$ length with a spacing $15 \mathrm{~cm}$ between plant to plant, at a uniform depth. Standard agronomic management practices were followed throughout the entire growing period as required. The data on 11 quantitative traits were recorded, out of 11 traits, observations on days to 50 per cent flowering, productive tillers per plant, head yield per plant $\left(\mathrm{g} \mathrm{plant}^{-1}\right)$, grain yield per plant $\left(\mathrm{g}\right.$ plant $\left.{ }^{-1}\right)$, fresh stover yield per plant ( $\mathrm{g}$ plant $\left.{ }^{-1}\right)$, dry matter yield per plant $\left(\mathrm{g}\right.$ plant $\left.{ }^{-1}\right), 1000$-grain weight $(\mathrm{g})$ and grain harvest index (\%) were recorded on plot basis. The data on remaining quantitative traits viz., plant height, ear length and ear diameter were recorded on five randomly selected representative plants in a plot. Average values of these five plants were computed and mean values were used for statistical analysis.

\section{Statistical analysis}

The data were subjected to statistical analysis using software Windostat Version 9.2. Principal component analysis (PCA) was performed for dimensional reduction and to know the importance of different traits in explaining multivariate polymorphism. Hierarchical cluster analysis was done following the minimum variance method of Ward (1963) based on squared Euclidean distances.

\section{Results and Discussion}

The analysis of variance for 60 inbred lines of Pearl millet for eleven quantitative traits is given in table 2. The results showed significant differences between the inbred lines for the characters studied $(p \leq 0.01)$, indicating a considerable amount of genetic variability and hence divergence analysis was carried out.

In principal component analysis, the number of variables is reduced to linear functions called canonical vectors which accounts for most of the variation produced by the characters under study. The Eigen values, per cent variance, per cent cumulative variance and factor loading of different characters studied are presented in table 3. The study identified four Principal Components (PCs) with Eigen value greater than 1.00 which accounted for 70.97 per cent of the total variation for discriminating the inbred lines of 
Pearl millet based on grain yield and its ten component traits. The percentages of total variability accounted by each of the first four principal components were 26.85, 18.06, 15.61 and 10.45 per cent, respectively. The traits, grain yield per plant and grain harvest index had positive contribution towards all the four PCs. The highest loading displayable variables on four PCs were grain yield per plant, grain harvest index, 1000 grain weight and productive tillers per plant. The PC1 classified inbred lines based on days to 50 per cent flowering, plant height, ear length, grain yield per plant, fresh stover yield per plant and grain harvest index. PC2 separated the material based on ear diameter and dry matter yield per plant. On the basis of head yield per plant and 1000 grain weight, PC3 separated the lines and PC4 separated the parental material based on productive tillers per plant. The results indicated the role of traits (specific to each PC) which contributed more towards divergence in discriminating inbred lines of pearl millet.

The first two principal components PC1 and PC2 with most of the desirable traits namely, days to 50 per cent flowering, plant height, ear length, ear diameter, grain yield per plant, fresh stover yield per plant, dry matter yield per plant and grain harvest index accounting for 44.92 per cent of total variation were considered to study grouping pattern of material under study.

The three dimensional scatter plot of PC1 and PC2 axes is represented in figure 1. The inbred lines represented by $5,9,16,17,24$, $25,30,34,36,39,42,45,46,56,58$ and 60 were accumulated on positive side of PC1 axis which accounted for high grain and stover yield characters.

The inbred line, 38 is represented on positive side of PC2 axis where the line has thicker ears and high stover yield character. The remaining lines were represented on positive side of both PC1 and PC2 axes indicating that these parental lines are characterised by high grain and stover yield with related traits (earliness, longer and thicker ears, high harvest index).

The hierarchical clustering pattern of parental lines of Pearl millet based on Mahalanobis squared Euclidean distance matrix obtained from quantitative data using Ward method is depicted in figure 2 .

The experimental material was assigned into eight clusters at an average $D^{2}$ value of 398.08, revealing the existence of variability among parental lines for the traits under study.

Cluster V was the largest with 18 lines followed by cluster II, cluster III, cluster VI, cluster I and cluster IV with 13, 12, 7, 5 and 4 lines, respectively. While, remaining clusters VII and VIII were solitary demonstrating the impact of selection pressure in increasing the genetic diversity. The cluster I comprised of four R-lines and single B-line, while cluster II had ten R-lines and three B-lines, cluster III had eight B-lines and four R-lines, cluster $\mathrm{V}$ had each of nine B- and R-lines, cluster VI had four R-lines and two B-lines. These results suggested clear differentiation of $\mathrm{R}$ lines and B-lines with minor exceptions. The preliminary evaluation of breeding material to identify potent parents for hybridization programme based on phenotypic data is fast, simple and can be considered as a general approach for assessing genetic diversity among genetically diverse lines. Likewise, grouping of genetic material based on quantitative data in pearl millet was reported by Shanmuganathan et al., (2006), Vidhyadhar and Devi (2007), Govindaraj et al., (2011), Drabo et al., (2013), Sathya et al., (2013), Upadhyaya et al., (2013), Sankar et al., (2014), Chaudhary et al., (2015), and Kumar et al., (2015). 
Table.1 List of 60 (27 B-lines and 33 R-lines) parental lines of pearl millet with pedigree details

\begin{tabular}{|c|c|c|}
\hline $\begin{array}{l}\text { S. } \\
\text { No. }\end{array}$ & $\begin{array}{l}\text { Parental } \\
\text { lines }\end{array}$ & Pedigree \\
\hline 1 & R1 & (AIMP 92901 S1-480-1-1-1-2-B-2 x ICMR 312 S1-3-2-3-2-1-1-B-B)-B-11-1-1-B \\
\hline 2 & R2 & [(IPC 1268×ICMV 91059 S1-58-2-2-2-1)×AIMP 92901 S1-296-2-1-1-1-B-B]-2-2-3-2-3 \\
\hline 3 & R3 & ((ICMV IS 94206 S1-15-2)×\{(SRC II C3 S1-19-3-2 x HHVBC)-5-3-1 $\})-B-13-4-2-1-1-1-1-3-2$ \\
\hline 4 & $\mathrm{R} 4$ & MDMRRC S1-329-1 \\
\hline 5 & R5 & RCB-2 S1-33-1-3-3-2-3-B-B-B-B-B-B-B \\
\hline 6 & R6 & ICTP 8202 S1-25-1 \\
\hline 7 & R7 & JBV 3 S1-257-1-4-1-B \\
\hline 8 & R8 & $\{[((\mathrm{MC} 94 \mathrm{S1} 1-34-1-\mathrm{B} \times \mathrm{HHVBC})-16-2-1) \times(\mathrm{IP} 19626-4-2-3)]-\mathrm{B}-28-3-2-2-2\} \times\{$ GB $8735-\mathrm{S} 1-15-3-1-1-3-4-2-2-2-1\}-\mathrm{B}-30-2-2-1-\mathrm{B}-\mathrm{B}-\mathrm{B}-1$ \\
\hline 9 & R9 & [(IPC 337×SDMV 90031-S1-84-1-1-1-1)×RCB-2-S1-144-2-2-2-1-1-1]-1-1-3-1 \\
\hline 10 & R10 & ICMS 7704-S1-127-5-1-5-1-1-3-3-2-B-B \\
\hline 11 & R11 & {$[((($ ICMV-IS 94206-15) ×B-Lines)-B-6) $\times($ MRC S1-156-2-1-B $)]-B-13-1-3-3-2-B$} \\
\hline 12 & R12 & MRC HS-219-2-1-2-B-B-B-B \\
\hline 13 & $\mathrm{R} 13$ & [((MC 94 S1-34-1-B x HHVBC)-16-2-1) × (IP 19626-4-2-3)]-B-37-1-1-1-2-B \\
\hline 14 & R14 & MRC HS-130-6-1-1-B-B-B-B-B-B \\
\hline 15 & $\mathrm{R} 15$ & [(((ICMV-IS 94206-15)×B-Lines)-B-6) $\times($ MRC S1-156-2-1-B)]-B-38-3-1-B-7-B \\
\hline 16 & R16 & LaGrap C2-S1-81-1-2-1-4-2 \\
\hline 17 & R17 & (RCB-2-S1-43-3-4 × MRC)-B-2-1-1-B-1-B \\
\hline 18 & $\mathrm{R} 18$ & (EERC-HS-32)-B-8-1-1-B \\
\hline 19 & R19 & (MC 94 C2-S1-3-2-2-2-1-3-B-B x ICMR 312 S1-3-2-3-2-1-1-B-B)-B-34-4-1-2 \\
\hline 20 & $\mathrm{R} 20$ & MDMRRC S1-1-278-2-5-3-B \\
\hline 21 & R21 & $\{(($ MC 94 S1-34-1-B $\times$ HHVBC $)-16-2-1) \times($ IP 19626-4-2-3)]-B-28-3-1-2-2 $\} \times\{$ MRC HS 225-3-5-2-B-B-B-B $\}-B-4-2-2-1-B-B$ \\
\hline 22 & R22 & ICMV 91059 S1-4-2-3-2-1-1-4-B-1-5-B-B \\
\hline 23 & R23 & (MC 94 C2-S1-3-2-2-2-1-3-B-B x AIMP 92901 S1-488-2-1-1-4-B-B)-B-30-3-4-2 \\
\hline 24 & R24 & MC 94 C2-S1-47-1-1-3-B-1-B-B \\
\hline 25 & R25 & [MC 94 C2-S1-3-1-3-1-4-B-B x LaGrap C2-S1-97]-B-11-1-1-2-B \\
\hline 26 & R26 & SDMV 95045 S1-7-2-4-2-3-2-1-B-B-B-B-8-1-1 \\
\hline 27 & R27 & Jakhrana $\times$ SRC II S2-215-3-2-1-B-3 \\
\hline 28 & $\mathrm{R} 28$ & ICMS 8511 S1-17-2-1-1-4-1-B-3-2-2-B \\
\hline 29 & R29 & [(IPC 1617×SDMV 90031-S1-84-1-1-1-1)×GB 8735-S1-25-4-4-1-1-3-1-1]-1-1-3-2-1-B-B \\
\hline 30 & R30 & MDMRRC S1-1-276-1-2-1-1 \\
\hline 31 & B31 & [(ICMB $95111 \times$ 9035/S92-B-3)-17-1-B-B-B-B \\
\hline
\end{tabular}




\begin{tabular}{|c|c|c|}
\hline 32 & B32 & [EEDBC S1-452-3-1-2-3-B-B-B-1 x B-bulk (3981-3989/S06 G1)]-4-2-4-B \\
\hline 33 & B33 & [ICMB $97444 \times(843 B \times x$ 405B $)-4]-1-2-B-B-B$ \\
\hline 34 & B34 & [IPC $1598 \times(843 \mathrm{~B} \times$ DSA 105B)]-51-3-B-B \\
\hline 35 & B35 & (ICMB 96555 x IP 10437)-2-4-2-B-6-1 \\
\hline 36 & B36 & (ICMB $89111 \times$ IP 9554-9)-4-2-2 \\
\hline 37 & B37 & [(MC 94 S1-34-1-B x HHVBC)-10-4-3-2-2-B-B-2 x (ICMR 312 S1-1-5-3-B x HHVBC)-7-1-1-1-B-B-B]-21-B-1-2 \\
\hline 38 & B38 & NC D2 S1-2-2-2-3-2-B-2 \\
\hline 39 & B39 & $(\mathrm{B} \times \mathrm{B}) \mathrm{F} 2 \mathrm{~S} 1-109-2-3-3-1-1-4$ \\
\hline 40 & B40 & (ICMB 03111 x \{(MC 94 S1-34-1-B x HHVBC)-16-2-1-1-1-1-B-B-5 x (MC 94 S1-34-1-B x HHVBC)-10-4-1-2-1-B-B-1-30-2-4-3-1)-13-2-3-3 \\
\hline 41 & B41 & $\{[(81 B \times$ SRL-53-1) $\times$ 843B]-3-5-3 x [(843B x 111B)-10-1-2-2]\}-226-B-2-B-B-B \\
\hline 42 & B42 & {$[\{26 \mathrm{~B} \times(81 \mathrm{~B} \times \mathrm{SRL} 50-1)\}-1-1-2 \times 852 \mathrm{~B}]-69-1-1$} \\
\hline 43 & B43 & ARD-288-1-10-1-2 (RM)-5 \\
\hline 44 & B44 & MC 94 C2-S1-3-1-3-3-1-1-2-B-B \\
\hline 45 & B45 & $\{($ MC 94 S1-81-1-B x HHVBC)-4-4-1 x (MC 94 S1-81-1-B x HHVBC)-4-2-4-10-3-1--B-B-B x ICMB 02777\}-24-3-2 \\
\hline 46 & B46 & EEDBC S1-465-3-2-5-5 \\
\hline 47 & B47 & (ICMB 93333 x ICMB 01222)-11-2-2-2-B-2-6 \\
\hline 48 & B48 & NC D2 BC7F4-12-1-2-3-1-4-3-B-B \\
\hline 49 & B49 & $690-93 \mathrm{~B}$ \\
\hline 50 & B50 & (SRC II C3 S1-19-3-2 x HHVBC)-12-4-1-3-2-1-B-2-B-4-B-B \\
\hline 51 & B51 & [HHV-S1-24-3-B-3-2 x (ICMB 96333 x HHVBC)]-19-B-1-3-B-B-B-B \\
\hline 52 & B52 & (ICMB 03111 x (MC 94 S1-34-1-B x HHVBC)-16-2-1-1-1-1-B-B-5 x (MC 94 S1-34-1-B x HHVBC)-10-4-1-2-1-B-B-1-30-2-4-2-1)-7-5-4-1-1 \\
\hline 53 & B53 & (ICMB 03111 x \{(MC 94 S1-34-1-B x HHVBC)-16-2-1-1-1-1-B-B-5 x (MC 94 S1-34-1-B x HHVBC)-10-4-1-2-1-B-B-1-30-2-4-3-1)-13-2-5-1 \\
\hline 54 & B54 & [ARD-288-1-10-1-2 (RM)-3 x B-bulk]-14-B-1-1 \\
\hline 55 & $843-22 B$ & $843-22 B$ \\
\hline 56 & $843 \mathrm{~B}$ & $843 \mathrm{~B}$ \\
\hline 57 & $\begin{array}{l}\text { ICMB } \\
95222 \\
\end{array}$ & ICMB 95222 \\
\hline 58 & $\begin{array}{l}\text { ICMR } \\
01004 \\
\end{array}$ & ICMR 01004 \\
\hline 59 & $\begin{array}{l}\text { ICMR } \\
01029 \\
\end{array}$ & ICMR 01029 \\
\hline 60 & $\begin{array}{l}\text { ICMR } \\
11003 \\
\end{array}$ & ICMR 11003 \\
\hline
\end{tabular}


Table.2 Analysis of variance for yield and its component traits in in Pearl millet

\begin{tabular}{|l|l|l|l|l|}
\hline \multirow{2}{*}{ S. No. } & \multirow{2}{*}{ Character } & \multicolumn{2}{|l|}{ Mean sum of squares } \\
\cline { 3 - 5 } & & $\begin{array}{l}\text { Replications } \\
\text { df (1) }\end{array}$ & $\begin{array}{l}\text { Treatments } \\
\text { df }(\mathbf{5 9 )}\end{array}$ & $\begin{array}{l}\text { Error } \\
\text { df }(\mathbf{5 9})\end{array}$ \\
\hline 1 & Days to 50 \% flowering & 0.53 & $100.62^{* *}$ & 11.75 \\
\hline 2 & Plant height (cm) & 11.56 & $1333.05^{* *}$ & 18.36 \\
\hline 3 & Ear length (cm) & 0.02 & $65.38^{* *}$ & 1.30 \\
\hline 4 & Ear diameter (cm) & 0.00 & $0.54 * *$ & 0.02 \\
\hline 5 & Productive tillers per plant & 0.02 & $0.73^{* *}$ & 0.05 \\
\hline 6 & Head yield per plant (g per plant) & 10.84 & $402.78^{* *}$ & 14.43 \\
\hline 7 & Grain yield per plant (g per plant) & 10.29 & $162.95^{* *}$ & 7.34 \\
\hline 8 & Fresh stover yield per plant (g per plant) & 16.54 & $1231.74^{* *}$ & 77.49 \\
\hline 9 & Dry matter yield per plant (g per plant) & 0.77 & $145.31^{* *}$ & 3.92 \\
\hline 10 & 1000 Grain weight (g per plant) & 0.00 & $15.19^{* *}$ & 0.36 \\
\hline 11 & Grain harvest index (\%) & 35.70 & $271.29 * *$ & 13.86 \\
\hline
\end{tabular}

df: Degree of Freedom; ${ }^{* *}$ Significant at $\mathrm{P} \leq 0.01$

Table.3 The eigen values, per cent variation and per cent cumulative variation for four Principal Components (PCs) and factor loading between PCs and traits studied in Pearl millet

\begin{tabular}{|c|c|c|c|c|}
\hline & PC1 & PC2 & PC3 & PC4 \\
\hline Eigen Value (Root) & 2.954 & 1.988 & 1.716 & 1.150 \\
\hline Per cent Variation & 26.852 & 18.069 & 15.603 & 10.455 \\
\hline Per cent Cumulative variation & 26.852 & 44.921 & 60.524 & 70.979 \\
\hline Character & \multicolumn{4}{|c|}{ Factor Loading } \\
\hline Days to $50 \%$ flowering & -0.377 & -0.093 & -0.367 & -0.330 \\
\hline Plant height $(\mathrm{cm})$ & 0.320 & -0.243 & -0.345 & 0.196 \\
\hline Ear length $(\mathrm{cm})$ & 0.168 & -0.482 & -0.371 & -0.119 \\
\hline Ear diameter $(\mathrm{mm})$ & -0.013 & 0.284 & 0.149 & -0.723 \\
\hline Productive tillers per plant & -0.430 & 0.179 & 0.038 & 0.332 \\
\hline Head yield per plant $\left(\right.$ g plant $\left.^{-1}\right)$ & 0.173 & -0.438 & 0.224 & -0.393 \\
\hline Grain yield per plant $\left(\mathrm{g}\right.$ plant $\left.^{-1}\right)$ & 0.490 & 0.100 & 0.134 & 0.107 \\
\hline Fresh stover yield per plant $\left(\mathrm{g}\right.$ plant $\left.^{-1}\right)$ & 0.277 & 0.263 & -0.515 & -0.027 \\
\hline Dry matter yield per plant $\left(\mathrm{g}\right.$ plant $\left.{ }^{-1}\right)$ & 0.077 & 0.441 & -0.358 & -0.188 \\
\hline 1000 grain weight $(\mathrm{g})$ & 0.229 & -0.022 & 0.334 & -0.039 \\
\hline Grain harvest index $(\%)$ & 0.371 & 0.347 & 0.114 & 0.034 \\
\hline
\end{tabular}


Table.4 Average intra (diagonal and bold) and inter cluster $\mathrm{D}^{2}$ values for eight clusters in Pearl millet

\begin{tabular}{|c|c|c|c|c|c|c|c|c|}
\hline Cluster & I & II & III & IV & $\mathbf{V}$ & VI & \begin{tabular}{|l|} 
VII \\
\end{tabular} & VIII \\
\hline I & 230.56 & 287.19 & 390.31 & 581.60 & 353.22 & 546.62 & 2008.93 & 1264.30 \\
\hline II & & 168.52 & 312.72 & 645.57 & 261.62 & 583.86 & 1648.75 & 1296.03 \\
\hline III & & & 211.99 & 509.60 & 278.77 & 523.85 & \begin{tabular}{|l|}
1376.72 \\
\end{tabular} & 1073.05 \\
\hline IV & & & & \begin{tabular}{|l|}
382.29 \\
\end{tabular} & 547.46 & 537.04 & 1737.60 & 1590.72 \\
\hline $\mathbf{V}$ & & & & & 147.90 & 291.13 & 1210.81 & 857.88 \\
\hline VI & & & & & & 231.14 & 1388.42 & 909.20 \\
\hline VII & & & & & & & 0.00 & 1234.81 \\
\hline VIII & & & & & & & & 0.00 \\
\hline
\end{tabular}

Table.5 Cluster means of sixty inbred lines for eleven quantitative traits in Pearl millet

\begin{tabular}{|c|c|c|c|c|c|c|c|c|c|c|}
\hline $\begin{array}{l}\text { S. } \\
\text { No. }\end{array}$ & Character & I & II & III & IV & $\mathbf{V}$ & VI & VII & VIII & Contribution $\%$ \\
\hline 1 & Days to $50 \%$ flowering & 57.80 & 53.31 & 54.00 & 51.75 & 52.06 & 53.67 & 42.50 & 56.50 & 0.40 \\
\hline 2 & Plant height $(\mathrm{cm})$ & 90.53 & 75.56 & 91.07 & 98.19 & 112.66 & 141.81 & 161.50 & 151.00 & 28.31 \\
\hline 3 & Ear length $(\mathrm{cm})$ & 11.90 & 9.80 & 14.01 & 16.81 & 16.54 & 20.63 & 25.33 & 41.00 & 6.33 \\
\hline 4 & Ear diameter $(\mathrm{cm})$ & 2.91 & 2.78 & 2.94 & 3.47 & 3.22 & 3.51 & 3.85 & 2.61 & 6.67 \\
\hline 5 & Productive tillers & 2.09 & 1.36 & 1.60 & 2.28 & 1.30 & 1.22 & 2.15 & 1.10 & 10.06 \\
\hline 6 & Head yield per plant (g per plant) & 16.21 & 18.03 & 26.11 & 44.72 & 25.05 & 26.65 & 97.50 & 23.39 & 5.03 \\
\hline 7 & Grain yield per plant (g per plant) & 10.28 & 10.84 & 16.58 & 32.82 & 16.10 & 19.51 & 40.50 & 7.90 & 3.05 \\
\hline 8 & Fresh stover yield per plant (g per plant) & 55.63 & 22.91 & 48.65 & 97.33 & 39.83 & 77.70 & 62.00 & 50.00 & 4.24 \\
\hline 9 & Dry matter yield per plant (g per plant) & 19.54 & 6.35 & 13.01 & 34.33 & 9.91 & 22.58 & 10.98 & 9.00 & 11.47 \\
\hline 10 & 1000 grain weight $(\mathrm{g})$ & 7.66 & 7.34 & 12.55 & 11.02 & 9.40 & 10.00 & 12.93 & 8.89 & 21.98 \\
\hline 11 & Grain harvest index $(\%)$ & 26.90 & 42.99 & 42.68 & 41.61 & 44.61 & 38.32 & 37.33 & 24.68 & 2.49 \\
\hline
\end{tabular}


Fig.1 Ward dendrogram of 60 inbred lines of pearl millet based on eleven quantitative traits (Scale on the bottom is squared Euclidean distance from $\mathrm{D}^{2}$ analysis)

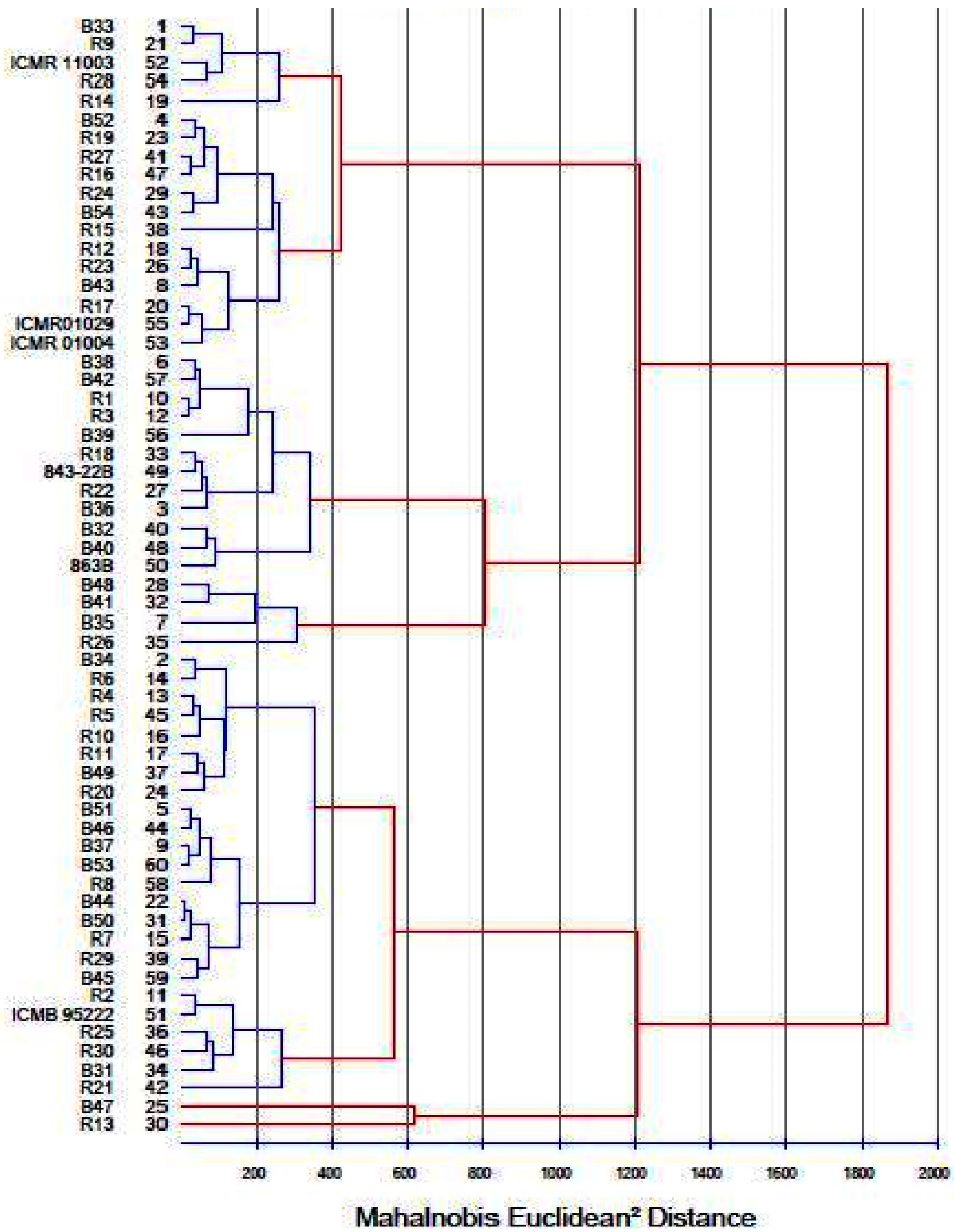


Fig.2 Three dimensional principal component scatter plot showing positions of sixty inbred lines of pearl millet

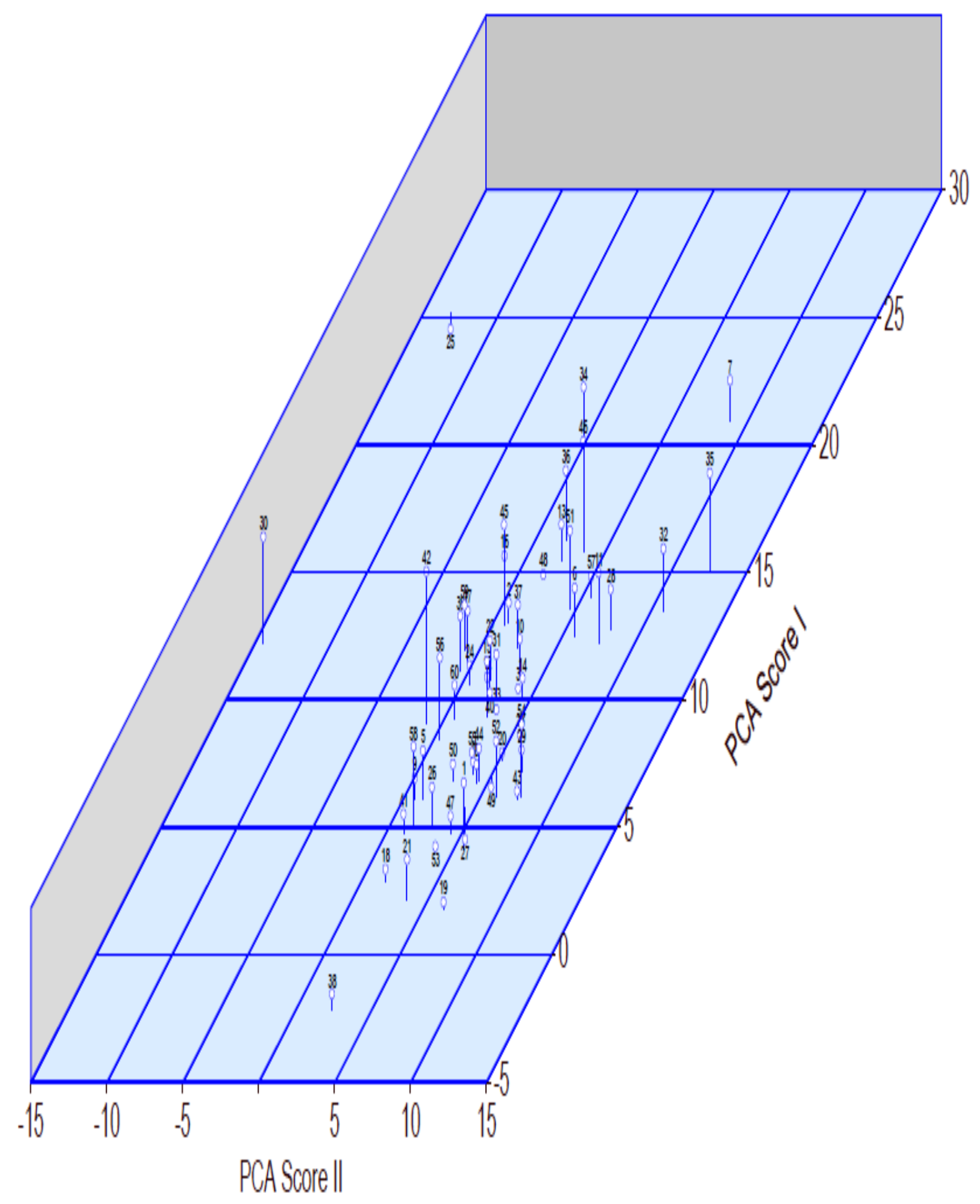


The average $\mathrm{D}^{2}$ values within (intra cluster) distance and between (inter cluster) clusters are given in table 4 . The average intra cluster distance ranged from 0.00 (cluster VII and VIII) to 382.29 (cluster IV). The maximum intra cluster distance was observed in cluster IV (382.29) followed by cluster VI (231.14), cluster I (230.56), cluster II (168.52) and cluster V (147.90). Therefore, selection within these clusters might be carried out on the basis of highest mean for desirable traits. Such intra cluster genetic diversity among the parental lines within the same group could be due to heterogeneity, pedigree and degree of general combining ability. The relative divergence of each cluster from other clusters (inter cluster distance) indicated high order of divergence between cluster I and cluster VII (2008.93) followed by that between cluster II and cluster VII (1648.75). Hence, the parents included in these clusters are genetically diverse and may have high heterotic response when used in hybridization programme. The selected lines could be used in inter crossing to develop base population with desirable characters. These findings were supported by reports of Vidhyadhar and Devi (2007) and Chaudhary et al., (2015). The minimum inter cluster distance was observed between cluster II and cluster V (261.62) indicating narrow genetic diversity.

The cluster mean and per cent contribution of each character towards genetic diversity is presented in table 5. There was wide range of variation in the cluster mean values for most of the characters under study. Cluster VII had highest mean values for plant height (161.50 $\mathrm{cm})$, ear diameter $(3.85 \mathrm{~cm})$, head yield per plant $(97.50 \mathrm{~g})$, grain yield per plant $(40.50 \mathrm{~g})$ and 1000 grain weight (12.93 g) and also recorded least number of days to $50 \%$ flowering (42.50). Cluster IV had shown highest mean values for productive tillers per plant (2.28), fresh stover yield per plant $(97.33 \mathrm{~g})$ and dry matter yield per plant
(34.33 g), cluster $\mathrm{V}$ for grain harvest index (44.61\%) and cluster VIII for ear length $(41.00 \mathrm{~cm})$. The characters contributing to most of the divergence should be given more importance for the purpose of effective selection and the choice of parents for hybridization. Plant height contributed maximum $(28.31 \%)$ towards genetic divergence followed by 1000 grain weight $(21.98 \%)$, dry matter yield per plant $(11.47 \%)$ and productive tillers per plant $(10.06 \%)$. The remaining characters contributed less genetic divergence indicating narrow genetic diversity for those characters. Shanmuganathan et al., (2006) and Kumar et al., (2015) reported similar results in Pearl millet. The distribution pattern of inbred lines on canonical graph matched mostly with the clustering pattern of hierarchical cluster analysis with few exceptions. This could be due to less contribution of first two principal components towards total variation. Such confirmatory results were also given by Gixhari et al., (2014), Chaudhary et al., (2015) and Kumar et al., (2015).

In conclusion, this study differentiated the parental lines of Pearl millet into eight clusters. On the basis of genetic distances, the lines of cluster VII, I and II could be used as parents in crop improvement programme to develop promising hybrids. In addition, it is essential to have knowledge on the general combing ability of the selected parents in the hybridization programme. Therefore, the parents and hybrids generated should be evaluated over different locations or seasons to launch successful hybridization programme and also to test the correlation between genetic distance and hybrid performance for grain and stover yield characteristics in Pearl millet.

\section{References}

Chaudhary, S., Sagar, P, Hooda, B.K. and Arya, R.K. 2015. Multivariate analysis of pearl 
millet data to delineate genetic variation. Forage Res., 40(4): 201-208.

Drabo, I., Zangre, R.G, Sawadogo, M. and Ouedraogo, M. 2013. Genetic variability and estimates of genetic parameters in Burkina faso's pearl millet landraces. Int. J. Agric. Forestry., 3(7): 367-373.

Gixhari, B., Pavelkova, M, Ismaili, H, Vrapi, H, Jaupi, A. and Smykal, P. 2014. Genetic diversity of Albanian Pea (Pisum sativum L.) landraces assessed by morphological traits and molecular markers. Czech $J$. Genet. Plant Breed, 50(2): 177-184.

Govindaraj, M., Selvi, B. and Kumar, I.S. 2011. Genetic diversity studies in indigenous pearl millet [Pennisetum glauccum (L.) R. Br.] Accessions based on biometrical and nutritional quality traits. Indian J. Plant Genet. Resour, 24(2): 186-193.

Gupta, S.K., Nepolean, T, Sankar, S.M, Rathore, A, Das, R.R, Rai, K.N. and Hash, C.T. 2015. Patterns of molecular diversity in current and previously developed hybrid parents of pearl millet [Pennisetum glaucum (L.) R. Br.]. Am. J. Plant Sci., 6: 1697-1712.

Khairwal, I.S., Rai, K.N, Andrews, D.J. and Harinarayana, G. 1999. Pearl millet Breeding, Oxford and IBH Publishing Co., Pvt. Ltd., New Delhi. 506.

Kumar, R., Verma, U, Malik, V. and Vart, D. 2015. Multivariate analysis for selection of diverse genotypes in pearl millet germplasm. Forage Res., 41(2): 73-77.

Sankar, S.M., Satyavathi, C.T, Singh, S.P, Singh, M.P, Bharadwaj, C. and Barthakur, S. 2014. Genetic diversity analysis for high temperature stress tolerance in pearl millet [Pennisetum glaucum (L.) R. Br]. Indian J. Plant Physiol., 19(4): 324-329.
Sathya, M., Vinodhana, N.K. and Sumathi, P. 2013. Hierarchial clustering of pearl millet (Pennisetum glaucum (L.) R.Br) inbreds for morpho-physiological traits. Int. J. Curr. Microbiol. App. Sci., 2(12): 647-652.

Satyavathi, C.T., Tiwari, S, Bharadwaj, C, Rao, A.R, Bhat, J. and Singh, S.P. 2013. Genetic diversity analysis in a novel set of restorer lines of pearl millet [Pennisetum glaucum (L.) R. Br] using SSR markers. Vegetos, 26 (1): 72-82.

Shanmuganathan, M., Gopalan, A. and Mohanraj, K. 2006. Genetic variability and multivariate analysis in pearl millet (Pennisetum glaucum (L.) R. Br.) germplasm for dual purpose. J. Agric. Sci., 2(1): 73-80.

Singh, A.K., Rana, M.K, Singh, S, Kumar, S, Durgesh, K. and Arya, L. 2013. Assessment of genetic diversity among pearl millet [Pennisetum glaucum (L.) R Br.] Cultivars using SSR markers. Range Manag Agrofor., 34 (1): 77-81.

Upadhyaya, H.D., Reddy, K.N., Singh, S., Gowda, C.L.L., Ahmed, M.I. and Ramachandran, S. 2013. Latitudinal patterns of diversity in the world collection of pearl millet landraces at the ICRISAT genebank. Plant Genet. Resour, doi: http://dx.doi.org/10.1017/S1479262113000 348.

Vidhyadhar, B. and Devi, I.S. 2007. Evaluation of germplasm for genetic diversity in pearl millet. J. Res. ANGRAU., 35(1): 119-123.

Ward, J. 1963. Hierarchical grouping to optimize an objective function. J. Am Stat Assoc., $38: 236-244$.

\section{How to cite this article:}

Radhika Ramya, A., M. Lal Ahamed and Rakesh K. Srivastava. 2017. Genetic Diversity Analysis among Inbred Lines of Pearl Millet [Pennisetum glaucum (L.) R. Br.] Based on Grain Yield and Yield Component Characters. Int.J.Curr.Microbiol.App.Sci. 6(6): 2240-2250. doi: https://doi.org/10.20546/ijcmas.2017.606.266 